\section{Competitividad y Marca de Destinos Turísticos en el Perú: Una Propuesta de Desarrollo 2019-2021}

\author{
Competitiveness and Brand of Tourist Destinations in Peru: \\ A Proposal for Development 2019-2021
}

\begin{abstract}
RESUMEN
En términos de la actividad turística la competitividad se suele reflejar en medio de una serie de elementos materiales y no materiales que determinan la calidad y diferenciación del producto turístico dentro de un área determinada, cuyo propósito mayor es el de satisfacer las necesidades de confort y bienestar de los turistas, el cual debe representar un esfuerzo de autoridades gubernamentales, gremios empresariales y académicos en su tratamiento, planteando modelos de negocios turísticos viables y sostenibles no solo económicamente sino social, cultural y ambientalmente; ya que toda opción de desarrollo turístico debe repercutir de forma efectiva en la mejora de la calidad de vida de la población del destino turístico. En los actuales mercados globalizados, el establecimiento de marcas de destino ayuda a identificar y diferenciar la gran diversidad de productos turísticos, formar un posicionamiento y tenerla como estrategia de generación de riqueza no solo debe servir para gestionar el valor de marca sino para preservar el valor del patrimonio socio cultural de las zonas focalizadas, evitar su politización y mantener la atracción de los viajeros y de los inversionistas debe ser un sendero que no se debe perder de vista.
\end{abstract}

Palabras claves: Competitividad turística; producto turístico; sostenibilidad; marca del destino.

\begin{abstract}
In terms of tourism activity, competitiveness is usually reflected in the midst of a series of material and non-material elements that determine the quality and differentiation of the tourism product within a given area, whose main purpose is to meet the needs of comfort and well-being of tourists, which must represent an effort of government authorities, business associations and academics in their treatment, proposing viable and sustainable tourism business models not only economically but socially, culturally and environmentally; since all tourism development options must have an effective impact on the improvement of the quality of life of the tourist destination population.

In the current globalized markets, the establishment of destination brands helps to identify and differentiate the great diversity of tourist products,
\end{abstract}

\section{María Guislena Cueto Luna}

mcuetol@hotmail.com

Universidad Nacional Mayor de San Marcos, Facultad de Ciencias Administrativas. Lima, Perú 
form a position and have it as a strategy of generating wealth not only serve to manage the brand value but to preserve the value of the socio-cultural heritage of the targeted areas, avoiding their politicization and maintaining the attraction of travelers and investors should be a path that we must not lose sight of.

Keywords: Tourism competitiveness; tourism product; sustainability; destination brand.

\section{INTRODUCCIÓN}

En el escenario del sector turismo uno de los aspectos que cobra cada día mayor relevancia es el de la competencia de los destinos turísticos, cada vez más importante en la gestión del destino así como en su planificación adecuada, para evitar un crecimiento desordenado del lugar y la saturación de sus espacios, como es el caso de Lunahuaná cuyo desorden se ve evidenciado principalmente por el turismo interno en temporada alta. Establecer estándares de calidad en los servicios de transporte, alojamiento, alimentación y venta de artesanías y/o souvenirs no es suficiente, el otorgar una licencia para el negocio no es suficiente frente a la escasez de control de la normatividad vigente, lo cual lleva a pensar en un replanteamiento de la actuación del estado a través de sus gobiernos regionales, locales y municipales.

Para lograr una adecuada competitividad de nuestros destinos turísticos a nivel internacional se requiere construir productos turísticos con alta utilización de recursos locales sostenibles para así poder conservar una determinada posición alcanzada en el mercado respecto a sus competidores más cercanos. Las sinergias de la capacidad competitiva de las empresas, la dotación de infraestructura, la disponibilidad de capital humano, y el entorno macroeconómico ha sido medianamente aprovechado tan solo en los circuitos turísticos del sur de nuestro país.

Otro aspecto muy importante es la sostenibilidad económica, social y ambiental de los destinos, que se logra a través de la gestión del mismo mediante una concepción de sociedad de bienestar que logre un crecimiento económico equitativo en beneficio de toda la población directa e indirectamente involucrada en la gestión de los productos turísticos de un determinado destino. Este aspecto es amplia- mente tratado por Barroso y Flores (20006) de la Universidad de Huelva en su enfoque sobre "La competitividad internacional de los destinos turísticos: Del enfoque macroeconómico al enfoque estratégico". En este sentido, nuestro país pese a haber bajado el ritmo de crecimiento de la actividad económica en general, todavía viene conservando buenas perspectivas macroeconómicas que nos llevan a ser recomendados para realizar inversiones seguras.

Una de las razones desarrolladas en este trabajo fue señalar el rol del Estado como promotor del desarrollo de empresas turísticas, de cadenas productivas turísticas eficientes, de investigación turística, y de asegurar los derechos de propiedad para poder promover mejor la inversión privada y garantizar la estabilidad jurídica dentro del sector, para ello se requiere la creación de puestos de trabajo con beneficios sociales y alta productividad, esto no quiere decir que el Estado deba abandonar su rol regulatorio entre la oferta y demanda turística a fin de corregir las distorsiones que se producen en el mercado.

Muy por el contrario, un Estado eficiente, eficaz debe distribuir de manera promotora de los escasos recursos públicos para poder asegurar el acceso a servicios básicos que garanticen no solo la sostenibilidad social a favor del bienestar general, sino que también promueva las condiciones apropiadas para el desarrollo de las actividades turísticas.

Asimismo, es importante mostrar una imagen autentica ligada a la sostenibilidad capaz de ser comercializada por incidir en aquellos aspectos que no solamente atraen por su identidad para visitarlo sino también por su contribución al cuidado ambiental a fin de poder mantener una relación armónica entre la sociedad y la naturaleza circundante, ello implica lograr un modelo de desarrollo económico exentó 
de amenazas a los recursos naturales actuales y futuros, debiéndose previamente señalar que desde hace varias décadas el turismo sostenible viene evolucionando en su definición, una de las más completas se señalaron en el Congreso de Internacional de Expertos Científicos del Turismo en 1991, donde se definió tal como lo cita (Valdés, 2001) como "todas las actividades turísticas que mantienen una relación de equilibrio entre los intereses sociales, económicos y ecológicos de las zonas receptoras"; para luego en posteriores eventos internacionales realizar extensiones hacia la protección de los espacios territoriales y los recursos naturales, considerando no solo aspectos de ocupación, explotación y contaminación sino también conservación, protección y sostenibilidad de la propia actividad turística en sus esencias culturales y sociales de las zonas receptoras.

Así con el devenir del tiempo, el gran peso lo han asumido las empresas privadas que han debido coadyuvar a incrementar la cultura de respeto al medio ambiente, ello a través de diversos programas funcionales al interior de sus organizaciones tales como: las de buenas prácticas ambientales, las de responsabilidad social que involucran a trabajadores y comunidad social circundante.

La creación de la marca de un destino turístico crea identidad y refleja un trabajo arduo que involucra a una serie de actores de la actividad turística con el fin de posicionarlo y comercializarlo como tal. En este sentido, el Estado peruano a través del Ministerio de Comercio Exterior y Turismo mediante la Comisión de Promoción del Perú de para las Exportaciones y el Turismo lanzo hace ocho años (marzo de 2011), la Marca Perú con el objetivo de promocionar la compra y el consumo de productos nativos peruanos, con ello impulsar el turismo en dichas zonas, además de atraer inversiones tanto locales como extranjeras. Siendo conveniente posicionar una marca específica para el sector turístico, tal vez no de forma gráfica sino conceptual, con una propuesta de valor que lo identifique como destino turístico.

El desarrollo del artículo plantea abordar la competitividad y el posicionamiento de la marca con un enfoque no convencional, dado que no solo se centra en la interpretación eco- nómica sobre opciones de ventajas comparativas o penetración de los mercados por medio de técnicas branding y neuromarketing, sino a través de una gran propuesta de valor que nos diferencie como cultura milenaria y emprendedora.

Los principales trabajos previos revisados y analizados sobre este tema se basan en el análisis crítico del Plan Estratégico 2012-2021, el cual plantea como objetivo principal posicionar al Perú como destino turístico competitivo y sostenible, incrementando el flujo de turistas nacionales y extranjeros como una manera de lograr posicionar al Perú como destino turístico tanto a nivel nacional como internacional. Igualmente es importante señalar que también existe la necesidad de diversificar y consolidar la oferta turística para de esta manera promover una cultura turística de manera interna y luego fomentar la labor de las instituciones públicas -agregadurías comerciales- encargadas de promover los destinos a nuestro país en el extranjero, tomado al turismo como una herramienta estratégica de desarrollo económico, social, cultural y ambiental.

Otras investigaciones importantes también examinan las características y las diversas fases hasta llegar a lograr el posicionamiento de un destino turístico, siendo catalogada como un instrumento de creación de riqueza, esto se debe basar en una percepción favorable de los turistas hacia el destino para poder motivar el viaje. Ello para otros investigadores sirve también para gestionar el valor de la marca -reconocimiento del nombre, calidad percibida, lealtad frente a la marca- que también incluyen aspectos funcionales, emocionales y en muchos casos evidencias de autoexpresión (Izaguirre, 2009).

Asimismo, se señala que la marca tiene que identificarse de acuerdo a las tendencias vigentes y a un selectivo proceso de elección de consumidores cuyas características deben ser de exigencia y bien informados, que dicho sea de paso en un mundo actual de alta conectividad global es cada vez más cambiante y plantean retos organizacionales tanto a nivel de las empresas como de las y organizaciones públicas promotoras de la actividad turística para lograr avanzar en el posicionamiento dentro de un mercado sumamente competitivo. 


\section{OJETIVOS DEL ENSAYO}

El presente artículo pretende exponer los factores que determinan la forma como el Perú debe competir para consolidarse como destino turístico, que incluye una característica de sostenibilidad y preservación del medio ambiente como indicador de desempeño importante para plantear los modelos teóricos de representación del sistema turístico de una localidad, mejorando su organización y gestión en el manejo de la actividad turística. Y de otro, examinar la importancia de la creación de marcas que corresponden a una concepción adecuada del destino que conlleve a consolidar la oferta turística.

En la primera parte se exponen los diversos conceptos de competitividad analizados para el caso del Perú, aspectos sobre el producto turístico, recursos locales y posición de mercado; en la segunda, se trata la sostenibilidad del desarrollo de las actividades turísticas desde un enfoque económico, social y ambiental; en la tercera la marca del destino turístico y sus necesidades objetivas y gráficas dentro de los actuales criterios globales de calidad, organización y gestión; en la cuarta se presentan las conclusiones y reflexiones.

\section{ARGUMENTACION}

\section{Construyendo las bases de una competitividad}

La base de la competitividad es el producto turístico entendido como el conjunto de bienes y servicios -elementos tangibles y no tangiblesque se encuentra situados en una determinada área y que ofrecen al turista una plena satisfacciones de sus necesidades de ocio, combinando sus deseos y expectativas con sus intereses sobre explorar una gran variedad de flora y fauna, riqueza paisajística y múltiples microclimas, culturas ancestrales con un patrimonio histórico y arqueológico sumamente valioso. Con todo ello, el Perú es un destino que cuenta con casi todos los tipos de turismo -natural, cultural, vivencial, de aventura, gastronómico, entre otros más específicos-; no obstante tan solo se ha logrado posicionar sólidamente un único destino a nivel internacional -Machu Picchu-, debido a la falta de asumir roles protagónicos tanto el Estado como el sector privado para ponerlos en valor y convertirlos en atractivos, debiendo sumarle las limitadas capacidades funciona- les que tienen los organismos de base para el desarrollo de la actividad turística, ya que por ejemplo, en el caso de las direcciones regionales de Comercio Exterior y Turismo estas no tienen la capacidad de realizar coordinaciones intersectoriales vitales para la (Regalado, ConexionEsan, p.1) "implementación de vías de acceso -terrestres, aéreas y/o fluviales-, velar por la seguridad ciudadana, asegurar la salubridad de los servicios de agua y alcantarillado". De modo que se garantice una estabilidad jurídica y económica para que los inversionistas del sector continúen materializando negocios que permitan desarrollar un mix óptimo sin saturar el destino, con un adecuado balance entre la oferta y la demanda turística.

Otro sector a intervenir es el académico, a través de las 53 facultades de turismo licenciadas por la Superintendencia Nacional de Educación Superior Universitaria (SUNEDU) en realizar investigaciones aplicadas -estudios de mercado, estudios de factibilidad, entre otros- al servicio del desarrollo turístico en sus zonas de influencia, acrecentando el flujo turístico actual y potencial. Es así, que una vez desarrollado el producto bajo estándares de calidad internacional corresponde promocionarlo -en ferias internacionales - a través de los mercados emisores de turistas adecuados y no tradicionales, especialmente los asiáticos ya que el americano o europeo ya tienen algún conocimiento de nuestro producto.

De la entrevista a representantes de los gremios empresariales se puede desprender la necesidad de diversificar la oferta turística de destinos con estrategias competitivas, cumpliendo con los indicadores óptimos de calidad exigidos por los turistas promedio. En este sentido los empresarios del sector deben conocer los estándares a través de los benchmarking con destinos internacionales semejantes, indagar frecuentemente lo que el mercado quiere a través de sondeo de expectativas, focalizado de manera precisa las necesidades del cliente turista en determinado destino, de tal manera que desee volver y recomendarlo.

Los esfuerzos por medir la competitividad turística datan aproximadamente de 1,990, desde donde se vienen proponiendo diversos modelos teóricos para el análisis de los destinos turísticos y entre los que destacan: Crouch 
y Ritchie, 1999; Dwyer y Kim, 2003; Gooroochurn y Sugiyarto, 2005; Hong, 2009; Jiménez y Aquino, 2012. Una característica común a todos ellos es la de relacionar factores como precios, infraestructura, tecnología, organización empresarial, sociedad y medio ambiente, entre otros condicionamientos foráneos; y que son claves para el análisis de este fenómeno económico de servicios. Cabe indicar que posteriormente se han adaptados modelos específicos para caracterizar los destinos turísticos a partir de los conceptos y herramientas de Michel Porter en el campo del turismo.

En el 2001 se puso en práctica un modelo desarrollado ya como sistema integral de medición y al cual se denominó "Índice de Competitividad Turística" de Gooroochurn y Sugiyarto, cuya metodología pasa por dos momentos. El primero, donde se seleccionaron inicialmente 23 ahora el actual en donde existen 90 indicadores que se resumen en ocho grandes grupos y luego son normalizados y adoptados por las $\mathrm{Na}$ ciones Unidas, este índice agregado para cada uno de los ocho grupos, se obtenía como una media aritmética de los índices normalizados. Luego esta metodología ha sido perfeccionada mediante un indicador mucho más ajustado y simplificado que obtiene una media ponderada
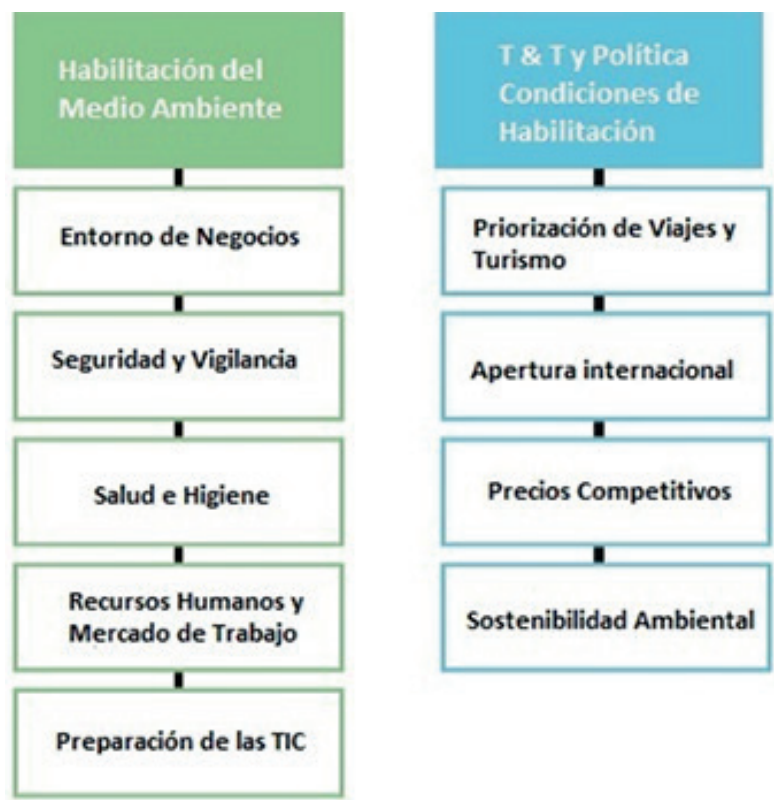

de cada uno de los ocho indicadores compuestos y donde los pesos se obtuvieron utilizando técnicas de análisis factorial.

Luego se realiza un ranking de índice de competitividad entre 200 países integrantes de la muestra con la finalidad de jerarquizar el grado de competitividad turística de los respectivos países. El aporte de Gooroochurn y Sugiyarto intenta solventar la ausencia de datos y permite comparar la competitividad de diferentes países. Sin embargo, tal como los mencionan otros estudiosos de la materia su principal desventaja se encuentra en los resultados.

Otro de los aspectos que cabe señalar son los factores reseñados en dicho índice, los cuales son catorce y donde destaca: el entorno institucional, la seguridad, el clima de negocios, la vigilancia, el transporte tanto aéreo como portuario, la salud e higiene, los aspectos laborales y de recursos humanos, la sociedad de la información, la apertura al exterior y los servicios disponibles a los turistas, la competitividad en precios, los recursos culturales y naturales disponibles en el destino, y las políticas de sostenibilidad ambiental y preservación de los recursos locales (Ver Figura 1).
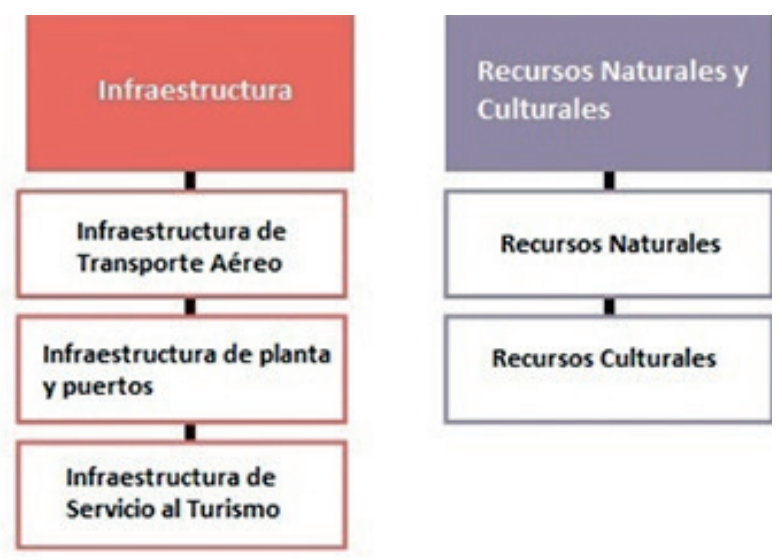

Infraestructura de

Figura 1. Factores del Índice de Competitividad Viajes y Turismo; publicado por primera vez en el 2007 por el Foro Económico Mundial con 124 países incluidos, hoy en día registra a más de 139; agrupados en cuatro grandes áreas: la habilitación del medio ambiente, las condiciones de politica de habilitación para viajes y turismo, la infraestructura con que cuenta, y la disponibilidad de recursos naturales y culturales.

Fuente: World Economic Forum (WEF) 
En el reporte de Competitividad en Viajes y Turismo 2017 vía WEF, nuestro país mejora siete posiciones al pasar del puesto 58 al 51 con respecto al 2015 (Ver Figura 2), teniendo como fortalezas los recursos naturales y culturales donde se ubica en los lugares cuarto y veinticuatro, respectivamente. Igualmente muestra una buena apertura internacional -puesto doce-; en infraestructura de servicios ocupo el puesto 45 , en recursos humanos y mercado de trabajo el 72 y en la priorización de viajes de turismo el puesto 79 , Ahora bien, entre las debilidades mostradas se encontraron las siguientes figuras: precios competitivos puesto 127 , infraestructura portuaria y terrestre puesto 109 , seguridad puesto 108 , salud e higiene puesto 91, entorno de nego- cios puesto 83, infraestructura para el transporte aéreo y sostenibilidad ambiental puesto 73, respectivamente (Ver Figura 2).

De otro lado, también se señala que nuestro país recibe cerca de 3,5 millones de turistas extranjeros, los que dejan divisas por cerca de US\$3,319 millones, con un gasto promedio por viajero de US\$960. También se destaca que a nivel mundial España por segunda vez consecutiva se ubica como el país líder, seguida de Francia, Alemania, Japón, Reino Unido. En tanto a nivel Latinoamericano (Figura 3), la encabeza México, seguida de Brasil, Panamá, Costa Rica, Chile, Argentina y Perú. Destacándose que en la mayoría de nuestros países latinoamericanos

\section{Key Indlcators}

\begin{tabular}{lr}
\hline International tourist arrivals & $3,455,709$ \\
\hline International tourism inbound receipts & US $\$ 3,319.7$ million \\
\hline Average receipts per arrival & US $\$ 960.7$
\end{tabular}

Sourcese World Touriem Orgenization (LNWTO) and World Travel and Tourlam Coundl (WTTC)

\begin{tabular}{lr}
\hline T\&T industry GDP & US $\$ 7,375.6$ million \\
$\%$ of total & $3.8 \%$ \\
\hline T\&T industry employment & 390,655 jobs \\
$\%$ of total & $2.5 \%$
\end{tabular}

\begin{tabular}{|c|c|}
\hline Performance Overvlew & Score $\longrightarrow-$ Highest score \\
\hline Pillar Rank/136 & Pillar Rank/136 \\
\hline International Openness 12th & Price competitiveness 127 th \\
\hline Prioritization of Travel \& Tourism 69th & Environmental sustainability 73rd \\
\hline ICT readiness 79 h & Air transport infrastructure 73 rd \\
\hline $\begin{array}{l}\text { Human resources and } \\
\text { labour market } 62 \text { nd }\end{array}$ & $\begin{array}{l}\text { Ground and port } \\
\text { infrastructure } 109 \text { th }\end{array}$ \\
\hline Health and hygiene 91st & $\begin{array}{r}\text { Tourist service } \\
\text { infrastructure } 45 \text { th }\end{array}$ \\
\hline $\begin{array}{l}\text { Safety and } \\
\text { security } 10 e \text { th }\end{array}$ & Natural resources 4 th \\
\hline $\begin{array}{l}\text { Business } \\
\text { environment 83rd }\end{array}$ & $\begin{array}{l}\text { Cultural resources and } \\
\text { business travel } 24 \text { th }\end{array}$ \\
\hline
\end{tabular}

Past performance

\begin{tabular}{lll}
\hline Travel \& Tourism Competitiveness Edition & 2015 & 2017 \\
\hline Rank & $58 / 141$ & $51 / 136$ \\
\hline Score & 3.9 & 4.0
\end{tabular}

Figura 2. Índice de Competitividad de Viajes y Turismo del Perú, muestra la performance que nuestro país tiene en términos de cada uno de los cuatro pilares básicos mostrados en la tabla 1; agregándose cifras generales como la llegada de arribos internacionales, divisas generadas por estos arribos tanto a nivel general como promedio; el aporte a la producción nacional y el número de trabajadores de la industria 


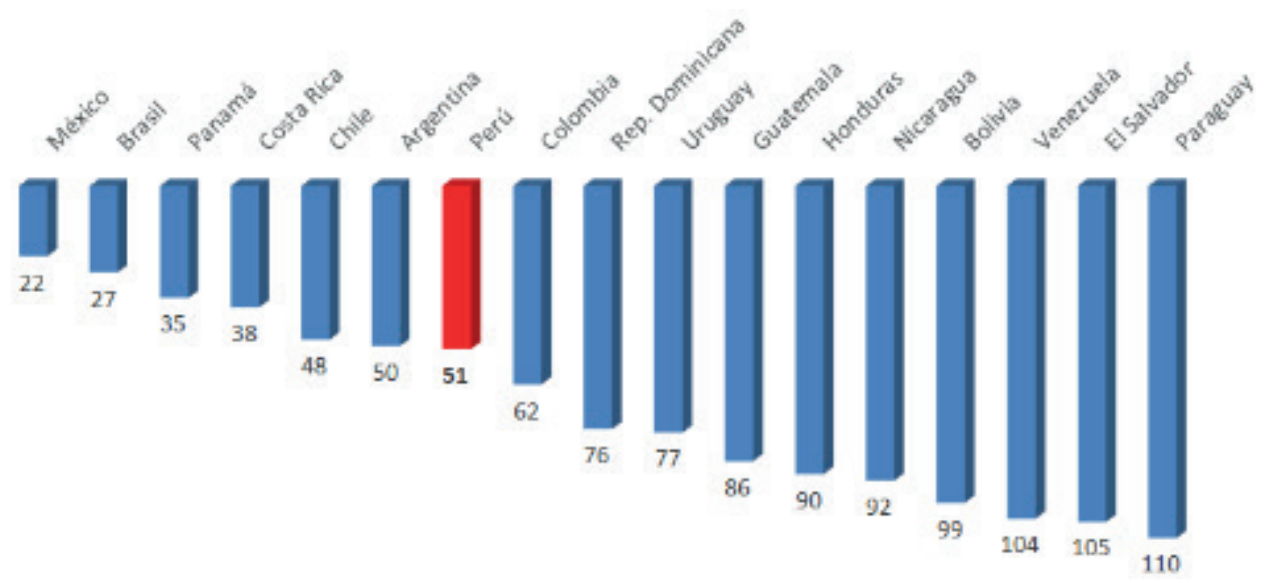

Figura 3. Ranking Latinoamericano de Competitividad Viajes y Turismo 2017, señala la posición que ocupan los países latinoamericanos en relación a la lista total, apreciándose que México y Brasil lideran al grupo.

Fuente: World Economic Forum 2017

se debe continuar mejorando los aspectos de seguridad y de protección al turista y poblador en general, a fin de crear entornos más propicios para las empresas turísticas y desarrollar infraestructura para mejorar la conectividad.

\section{Recursos ordenados ayudan a su conservación}

El ordenamiento de los recursos turísticos por la parte cultural o permanente es según la geógrafa mexicana Ana García Silberman la más aceptada, siendo también validas contemplar los naturales -donde se desprenden tres categorías: geomorfológicos -litorales, lagunas, corrientes de agua, volcanismo, montañismobiogeográficos -bosques, arboles, selvas, campo de flores, especies raras, zonas de caza o pesca-, y mixtos -montañas y bosques, llanuras y estepas, paisajes submarinos, oasis y desiertos-, algunos otros autores señalan también los creables que tan solo son aprovechables por un lapso de tiempo que duren dado la perdida de interés de acuerdo al momento en que se utilicen. En este sentido, falta mucho camino por recorrer para lograr un adecuado ordenamiento y conservación, especialmente en las zonas andinas del país.

Siendo la actividad turística un servicio desarrollado en un espacio determinado es prácticamente imposible que no se generen conflictos en los mismos, especialmente en los naturales, ya que si bien se reconocen los beneficios económicos y sociales que genera esta actividad también es importante señalar los perjuicios que conlleva su explotación no racional, teniendo impactos adversos sobre los recursos renovables y no renovables, los lugares de mayor impacto significativo son las zonas de costa, ríos, lagos y montañas, dado que son ecosistemas frágiles con una gran variedad de especies, costas, ríos, lagos y montañas, que son ecosistemas frágiles con una gran variedad de especies, cuyo uso intensivo y no sustentable produce perdidas no reversibles (INEI, 2000). Esto es ocasionado por el alto flujo de visitantes sobre una zona, este nivel de impactos para Blanco (1998) se relaciona directamente a distintas variables como la duración de la visita, estacionalidad considerada, tipología y comportamiento del usuario, distribución de los usuarios por el área protegida, fragilidad ecológica del ambiente considerado y medidas de gestión y restauración que los gestores deciden aplicar.

En términos generales se pueden señalar que los impactos generados en el turismo de orden ecológicos, económicos, sociales y culturales; hay que reconocerlos y sistematizarlos, esto constituye el primer paso para atender de manera sistemática, como lo señala (Tinoco, 2003). Para tales propósitos hace ya un buen tiempo se creó en nuestro país el Sistema Nacional de Áreas Naturales Protegidas (SINANPE) a fin de priorizar las labores de mitigación pertinentes, para los cuales se establecieron las categorías de Santuarios Nacionales, Santuarios Históricos, Parques Nacionales, Reservas Paisajísticas, Reservas Nacionales, Reservas Comunales, Refugios de Vida Silvestre, Bosques de Protección y Cotos de Caza. Sin embargo, los 
resultados son sumamente escasos frente al uso recreativo cada vez más frecuente, ya sea por falta de implementación de los planes desarrollados, carencia de personal y equipos para desarrollar su labor de manera apropiada.

Otro problema frecuente en los destinos turísticos, es la gran afluencia de visitantes y su incremento desmedido, que inclusive rebasan la demanda de servicios básicos de infraestructura y tal como lo señala el Banco Mundial:

Debe considerarse el impacto visual y físico de los alojamientos y demás estructuras que serán construidas para servir a los turistas. La facilidad de construcción y el diseño eficiente, debe equilibrarse con las consideraciones de armonía con el ambiente natural y el contexto sociocultural circundante.

Ello, también tiene un componente social importante tal como lo señalan los expertos, es que a través de la carga social referida a la sensación de fatiga que tienen los diversos grupos de personas cuando visitan un determinado lugar con elevada concentración de visitantes, esta masificación hace muchas veces que su experiencia sea valorada de forma negativa, independiente de las virtudes naturales del lugar visitado.

Otro aspecto social muy marcado constituye la percepción que tienen y desarrollan los lugareños frente al establecimiento de áreas protegidas, Tello (2000) señala que "muchos de los pobladores locales pueden percibir que las áreas protegidas fueron establecidas más para satisfacer los intereses extranjeros que los suyos". Trabajar sobre una opción preconcebida de que todo desarrollo turístico debe repercutir de forma efectiva sobre la mejora de la calidad de vida de la población residente en la zona e incidir en el enriquecimiento sociocultural de cada destino es hoy en día un pilar fundamental para una amplia participación y colaboración por parte de todos los actores involucrados en la actividad turística, tanto a nivel públicos como privados implicados en la actividad turística tal como lo señala la Carta Mundial de Turismo Sostenible de 2015, concertación que debe basarse en mecanismos eficientes y eficaces de cooperación y asociación en todos los estamentos geoespaciales desde el destino local, regional, nacional e internacional.

\section{Hacia consolidar un posicionamiento de mercado}

Establecida las dos premisas iniciales como lo son tener productos turísticos con alto contenido de valor añadido y equilibradamente tratado, queda precisar la importancia de un adecuado posicionamiento en el mercado tanto nacional como internacional. En el primer caso, la estabilidad macroeconómica del país ha permitido mantener un crecimiento de $6,5 \%$ en el turismo interno en los últimos cinco años a tal punto que según las últimas cifras de Promperu (2017), revelan 1,4 millones de residentes realizaron alguna visita al interior por vacaciones, recreación u ocio, esto favorece la descentralización económica y genera nuevos puestos de trabajo en las regiones. Sin embargo, se nota una concentración de tan solo 6 ciudades emisoras -Lima, Arequipa, Chiclayo, Piura, Trujillo y Huancayo- generaron el $84 \%$ de las visitas con un promedio de gasto de S/. 402 y una estadía promedio de 4 noches, siendo las ciudades más visitadas: Lima (23\%), Ica (12\%), Arequipa (9\%), y Junín con Piura (7\%); realizándose actividades como: pasear por parques o plazas, visitar iglesias, catedrales y conventos, comprar artesanías, pasear por lagos y lagunas, comprar dulces típicos. Igualmente se aprecia que el medio de transporte más utilizado es el terrestre (69\%), seguido del aéreo (14\%); y los lugares de alojamiento predominantes son la casa de familiares y amigos (32\%) y los hostales (29\%), tan solo un $17 \%$ utiliza hoteles de 1 o 2 estrellas.

Ahora bien, que hacer para promover una mayor movilidad del turismo interno, para el gremio privado liderado por Canatur (2016) se trataría de impulsar obras de infraestructura a fin de facilitar el acceso a los diversos espacios turísticos, siendo necesario también revisar la politica aerocomercial, fomentar una mayor inversión en la continuidad de las autopistas con Chile, Ecuador y Bolivia, incluyendo las ciudades principales del turismo fronterizo, otra de las medidas señaladas se refiere a la facilitación tributaria que promuevan la inversión privada, incluyendo la simplificación de trámites y fomentando la estandarización de los servicios turísticos, a lo que habría que agregar que también se requiere una mayor promoción privada a través de los diversos gremios empresariales ligados a los destinos turísticos, y por parte de 
la academia realizar campañas continuas de concientización.

Resulta muy cierto que la gran fuente económica del turismo la proporciona el turismo receptivo y en este sentido el país ha tenido un crecimiento (8\%) turístico extranjero sostenido casi el doble del crecimiento del producto bruto interno (PBI), durante el último año (2017) registrado por las estadísticas oficiales genero más de 1,3 millones de empleos y logro un ingreso de divisas de US $\$ 4,573$ millones. Ya hace algunos años Promperú inicio el estudio de una serie de perfiles de los consumidores turísticos extranjeros; cabe señalar que hasta el momento los turistas en un $60 \%$ son procedentes de Latinoamérica, que se quedan un promedio de 10 noches, sus motivaciones están en las vacaciones (68\%), visita a familiares y amigos (14\%), y negocios (13\%). Estos tienen un gasto promedio de US\$1,064, siendo Chile, Estados Unidos, Ecuador, Argentina y Colombia los principales emisores, siendo sus motivos de viaje en un $71 \%$ por vacaciones, recreación $\mathrm{u}$ ocio, seguido de visitas a familiares y amigos $(12,4 \%)$, así como también por negocios (13\%), sus ingresos anuales en un $75 \%$ son mayores a los US $\$ 40,000$, el $68 \%$ utiliza el transporte aéreo a su llegada como para sus traslados al interior del país. Igualmente, los viajeros extranjeros en un $83 \%$ utilizan hoteles desde 1 a 5 estrellas para pernoctar en sus días de estadía, y un $98 \%$ utiliza restaurantes como actividad complementaria.

Luego de la llegada de los visitantes Latinoamericanos le siguen los Estadounidenses, Europeos y en menor medida Asiáticos, pese a ser un mercado cada vez más protagónico a nivel internacional, según Euromonitor International (2016), ya que posee un nivel de gasto medio superior a los US $\$ 1,300$ por persona, realizan compras directas de autos, pasajes, alojamiento y en la mayoría de veces de forma Online; esfuerzos por realizar mayores perfiles selectivos en los mercados de China, Japón, Australia, Corea del Sur y Rusia es la tarea pendiente.

Incursionar en el concepto de economía compartida en turismo es vital para ganar dichos mercados de población joven entre 25 y 34 años que utiliza muchos las plataformas informáticas, dado que los viajes (tres actores de dicha economía serian Airbnb -compañía que facilita reservas de alojamiento-, Uber -empresa de transporte compartido que mediante un aplicativo conecta a pasajeros con conductores autónomos-, HomeAway -negocio de alquiler para vacaciones-) hoy en día suponen no solo el alojamiento y el transporte sino diversas oportunidades a futuro, para ello debe haber un crecimiento generalizado de los servicios colaborativos que no limite a determinadas zonas rurales o en las que no tienen fácil acceso a la tecnología y al Internet.

\section{La sostenibilidad una necesidad dentro del turismo}

Es preciso señalar que el sentido de sostenibilidad implica por un lado examinar en primer lugar las necesidades humanas y proyectarla frente a la solidaridad entre las generaciones implicadas en el cambio. En cuanto a las necesidades conllevan a realizar una introspección de las reales necesidades presentes y futuras, ya que la adopción de modelos de producción de las sociedades modernas ha difundido la obligación que sean valores que se deben dar en toda sociedad de principios económicos, sociales y ambientales. Ahora bien, a medida que la actividad turística se va volviendo una de las labores de servicios con mayor crecimiento a nivel mundial es que surgen conceptos como turismo sostenible, que según Barrera (2012) "el turismo que tiene plenamente en cuenta las repercusiones actuales y futuras, económicas, sociales y medioambientales para satisfacer las necesidades de los visitantes, de la industria, del entorno y de las comunidades anfitrionas".

Plantear bajo este contexto la importancia del cuidado del medio ambiente basado en el turismo sostenible es vital para garantizar que las actividades turísticas causen el menor deterioro ambiental, de allí que el turismo sostenible se ha convertido en una condición fundamental para fomentar la preservación, conservación y cuidado del medio ambiente. En este sentido, cabe decir que durante las últimas dos décadas se ha acentuado una creciente sensibilidad social por el mantenimiento de la calidad ambiental, ya que sus efectos de degradación a nivel paisajista, ambiental, social y cultural en el turismo de masas ha generado en todo el mundo problemas sobre sectores económicos básicos como son: la ali- 
mentación, el transporte, los seguros, la energía, la tecnología, la construcción, etc.

Bajo este contexto, es que suelen presentarse algunos espacios turísticos con fuertes presiones territoriales, algunos intereses privados y públicos enfrentados, por ello como (Agenda 21, 2012) lo señala "es necesario un enfoque que posibilite la confluencia de las diversas posiciones antagónicas que contemplen en la medida de lo posible establecer prioridades de los agentes sociales locales y los demás sectores económicos" esto resultara factible a partir de implementar modelos de participación ciudadana para lograr una buena gestión sostenible.

Es por ello, que las interrelaciones de los turistas con sus espacios (Venegas, 2016) señala que "los nuevos turistas buscan espacios con menor impacto sobre el medio ambiente y con una mayor integración de las características sociales y culturales de la localidad para de esta manera reducir los efectos negativos del turismo sobre el medio". Por lo mismo es importante hoy en día asegurar la puesta en valor de una amplia diversidad de tipos de turismo que integren de manera armoniosa las necesidades de este cliente de servicios y la población de la zona. Esto se complementa perfectamente con la concepción del turismo contemporáneo que trata de implementar modelos de desarrollo turísticos sostenibles y sustentables que sean compatibles con la conservación de recursos naturales y el incremento de la equidad y justicia social. Por ello, el componente de sostenibilidad es hoy en día la única opción válida dentro de la actividad turística que pretenda mejorar la calidad de vida de la población circundante a los proyectos turísticos, sino que significa sentar las bases de una futura vida más equilibrada en el planeta.

\section{Creando marcas de destinos objetivas más que gráficas}

Muchas veces nos preguntamos porque es importante construir una marca; y en el sector turismo resulta más aun fundamental, dado que institucionalizar un lugar como destino turístico y coadyuvar a lograr un mejor posicionamiento de lugar dentro de determinado segmento de mercado. Es decir, como afirma Norberto Chaves (2016) "es declarar que aquel lugar no es meramente un sitio digno de visitar- se sino un lugar turístico", un espacio en cuyo centro está el turismo; el solo realizar sistemáticamente promoción turística de un lugar es, de por sí, construir marca de destino. Pero ello no exige, necesariamente crear una marca gráfica. Poseer una marca conceptual no implica desarrollar una marca gráfica, tan solo será necesario cuando resulte indispensable para señalar y determinar un lugar de destino o cuando se pretenda implementar una politica turística basada en ella.

Desde el año 2002, el Ministerio de Comercio Exterior y Turismo mediante Promperú comenzó a utilizar diversos medios e instrumentos para impulsar el turismo y la inversión privada, lanzando iniciativas como de crear la Marca Perú en el año 2011. Esta sobre la base de una asociación entre el Estado, las empresas y startups peruanas con el objetivo de promover la compra y el consumo de productos elaborados en el Perú; adicionalmente se señalaron tareas como: la de impulsar el turismo, las exportaciones y atraer inversiones haciendo uso de las técnicas avanzadas del marketing como el branding y el neuromarketing, Los resultados al parecer han sido favorables dado que según la consultora Bloom determino que la Marca Perú ascendió once posiciones y ubicándolo en el puesto 41 del listado global del reporte "Country Brand Ranking" correspondiente al periodo 2017-2018.

Esto encierra una estrategia identificadora general de Marca País creada hace ya varias décadas por el asesor del gobierno británico Simon Anholt y en donde la finalidad inicial era que las naciones sean tratadas como marcas e incorporen técnicas de gestión empresarial adoptando un lenguaje y los diversos métodos del marketing y la gestión comercial de los últimos veinte años. Ello a decir de los expertos -Nadia Kaneva, profesora de la universidad de Denver y una de las mayores autoridades en el análisis del fenómeno de las marcas país en el mundo- señalan que en sus inicios esta fue utilizada efectivamente para atraer turistas y generar inversiones privadas, pero hoy en día existe una fuerte tendencia a ser utilizada con fines políticos, tratando de crear una especie de sentido de identidad y orgullo nacional entre sus pobladores. Esto funciona correctamente si un país desea recuperarse de un conflicto im- 
portante como en el caso de aparheid en Sudafrica o el Kosovo independiente luego de la guerra con Serbia; aun así es difícil probar el logro de sus objetivos fundamentales, dado que posteriormente a las campañas suelen persistir las profundas desigualdades sociales y políticas. Adicionalmente, al hecho que diversos países se esfuerzan por manejar su marca para atraer a los medios internacionales con la finalidad de conseguir transacciones de comercio exterior con fines específicos y no del interés nacional.

También existe interpretaciones de expertos más sociológicas -Cuevas Calderón Magister en Estudios Culturales de la Pontificia Universidad Católica del Perú, 2014- en la que sostiene que la era del consumismo actual es una ideología y que en la actualidad los ciudadanos peruanos no son los únicos que en el mundo tiene el deseo de llevar este estilo de vida, pese a que no se ha reflexionado bien sobre las consecuencia políticas y ambientales, esto en su opinión cambia a los habitantes de una nación de ciudadanos a consumidores -en el caso peruano seria cuando se intenta asociar a nuestro país con un lugar mágico y místico, aduciendo que son las características básicas que exigiría el nuevo mercado turístico internacional- a un precio muy elevado, ya que no se piensa en la necesidad de conservar el patrimonio y la preservación de su valor cultural sino que conlleva a una visión mediática y utilitaria que concibe los recursos turísticos como un activo cualquiera, carente de cualquier valor intrínseco para las comunidades receptoras de un determinado flujo turístico.

Bajo este contexto y en términos prácticos podemos afirmar que la promoción turística que utiliza marcas de destino genéricas y gráficas se convierte hoy en día en un elemento competitivo valioso e ineludible, para que una marca turística describa de manera simplificada una serie de valores y atributos integrantes de la oferta turística de un país, y que garantiza tener una estrategia efectiva dirigida a conseguir consumidores efectivos reales y potenciales productos y servicios que puedan ser fidelizados a mediano y largo plazo.

\section{CONCLUSIONES}

El Perú posee un gran potencial de recursos turísticos que articulados adecuadamente se pueden convertir en productos turísticos muy competitivos en los diversos tipos de actividades turísticas tradicionales y de vanguardia a nivel mundial y son necesarios esfuerzos conjuntos entre los diversos actores de la actividad turística; las autoridades gubernamentales potencializando sus capacidades funcionales y articulando sus coordinaciones intersectoriales en beneficio de optimizar la calidad en la gestión de los productos turísticos.

Los gremios privados tanto de empresas como académicos deben poner un mayor compromiso con la puesta en valor de los patrimonios culturales y socio-económicos de los destinos turísticos identificados y seleccionados para ser promocionados y apoyados como proyectos de inversión turísticos prioritarios.

La sostenibilidad ambiental resulta vital para mirar el desarrollo actual y futuro de la actividad turística y conlleva a mirar las reales necesidades humanas de los lugareños y la solidaridad entre generaciones presente y por venir. Esto tal vez implique un cambio de modelos de producción de los servicios a fin de saber reconocer y sistematizar con la debida anticipación los impactos ecológicos, económicos, sociales y culturales que genera el turismo, esto indudablemente constituye el primer peldaño para atender de manera selectiva y priorizada las labores de mitigación pertinentes a través de implementar planes de desarrollo integrales.

Lograr un posicionamiento tanto en el mercado nacional como internacional hoy en día es vital para continuar con la dinámica de crecimiento y desarrollo no solo de las actividades turísticas sino en muchos casos todas las del propio país en su conjunto; dado que de manera interna, en este sentido podrían ayudar una serie de normas de simplificación que promuevan un mayor impulso de la inversión privada en el sector y el fomento de estándares de servicios que mejoren la calidad de los productos turísticos.

A nivel internacional es importante trabajar con mayor profundidad en el conocimiento de los perfiles de los turistas asiáticos -especialmente chinos, japonés y coreanos- que hoy en día representan un segmento muy atractivo tanto por los días de pernoctaciones como por 
el nivel de gasto promedio, con el fin de lograr un buen posicionamiento en dichos mercados.

La importancia de crear una marca de destino para lograr un rápido posicionamiento en el segmento de mercado turístico deseado debe centrarse en las herramientas de gestión comercial y métodos de marketing; ya que sus aplicaciones políticas podrían ser muy negativas para el desarrollo de la actividad turística. Asimismo, la marca del destino debe considerar una concepción que lleve a la preservar el patrimonio, cultural y social de las comunidades receptoras y utilizar marcas de destino tanto genéricas como gráficas.

\section{AGRADECIMIENTOS Y RECONOCIMIENTOS}

A mi Madre por ser la luz que guía siempre mi camino, a mi hija Claudia por ser mi inspiración constante de vida, a mi hermano Armando con quien comparto la pasión por la investigación académica; y finalmente a la Facultad de Ciencias Administrativas de la UNMSM por bridarme la oportunidad de expresar algunas ideas y experiencias dentro del campo profesional del turismo.

\section{REFERENCIAS BIBLIOGRÁFICAS}

Batista-Sánchez, E., González-Ferrer, J. R., González-Camejo, I.T. y Leyva-Cardeñosa, E. (2017). Procedimiento para medir la imagen de destinos turísticos. Centro de Información y Gestión Tecnológica de Holguín, 23, (3), 1-18. Recuperado de http://www.redalyc.org/articulo. oa?id=181552082001

Cuevas Calderon, A. (2014). El sello de nuestra identidad: Marca Perú Farsa Perú. GT11: Comunicación y estudios socioculturales, 2-23. Recuperado de http://congreso.pucp.edu.pe/alaic2014/ wp-content/uploads/2013/09/GT11-Elder-Alejandro-Cuevas-Calder\%C3\%B3n.pdf

Izaguirre Sotomayor, (2009). “Contribución Teórica para la Construcción de la Marca de Destino Turístico Perú". Recuperado de http://www. revistacultura.com.pe/revistas/RCU_23_1_ contribucion-teorica-para-la-construccion-de-la-marca-del-destino-turistico-peru.pdf

Martínez Pastor, E. y Nicolás Ojeda, M. A. (2013). La construcción de la imagen de marca "Andalucía" como destino turístico a través de las campañas publicitarias "small you are in Andalucia" y "Andalucía te quiere". Cuadernos de Turismo, 32, 207-228. Recuperado de http://www.redalyc.org/articulo.oa?id=39827029010
Matos Cámara, R. y San Martín Gutiérrez, S. (2012). Análisis sobre la reputación de marca, las emociones y la confianza como formadoras de la satisfacción del turista. Contaduría y Administración, 57 (4), 253-286. Recuperado de https://www.redalyc.org/articulo.oa?id=39524375012

Mazaro, R. y Varzin G. (2008). Modelos de competitividad para destinos turísticos en el marco de la sostenibilidad RAC. Revista de Administração Contemporânea, 12 (3), 789-809. Recuperado de http://www.redalyc.org/articulo. oa?id=84012309

Medina Molina, C., Rey Moreno, M. y Rufín Moreno, R. (2010). Imagen de los destinos turísticos urbanos y lealtad del turista...: ¿Actitud o comportamiento? Estudios y Perspectivas en Turismo, 19, (2), 279-298. Recuperado en http://www. redalyc.org/articulo.oa?id=180713901007

Pascarella R. y Rubens Fontes Filho, J. (2010). Competitividad de los destinos turísticos, modelo de evaluación basado en las capacidades dinámicas y sus implicancias en las políticas públicas. Estudios y Perspectivas en Turismo,19, 1-17. Recuperado en https://www.redalyc. org/busquedaArticuloFiltros.oa?q=competitividad $\% 20$ de $\% 201$ os $\% 20$ destinos $\% 20$ turisticos $\% 20$ modelo $\% 20$ de $\% 20$ evaluacion $\% 20$ basado\%20en\%20las\%20 capacidades\&idp=1

Regalado, O., Berolatti, C., Martínez, R. y Riesco, G. (2011). Identidad competitiva y desarrollo de marca para la ciudad de Arequipa. Gerencia para el Desarrollo, 26, 11-178. Recuperado de http://repositorio.esan.edu.pe/bitstream/ handle/ESAN/134/Gerencia_para_el_desarrollo_26.pdf?sequence $=1 \&$ isAllowed $=y$

Regalado, Otto, ConexiónEsan, (Agosto 2011). De Recursos a Productos Turisticos

https://www.esan.edu.pe/conexion/bloggers/ hablando-de-servicios/2011/08/de-recursos-a-productos-turisticos/

Rial Boubeta, A., García Carreira A. y Varela Mallou J. (2008). Una aplicación metodológica para el estudio de la imagen de marca de un destino turístico. Pasos. Revista de Turismo y Patrimonio Cultural, 6 (1), 1-10. Recuperado de http:// www.redalyc.org/articu lo.oa?id=88160101

Ruiz Carrasco, N. (2014). Estrategia de marca de destino turístico basado en sus activos tangibles e intangibles. Caso de estudio: Tijuana (México) y Gandía (España). Universidad Politécnica de Valencia, Escuela Politécnica Superior de Gandía, 1-73. Recuperado de https://riunet. 
upv.es/bitstream/handle/10251/36040/PROYECTO.pdf?sequence=1

San Martín Gutiérrez, H. y Rodríguez del Bosque, I. (2010). Los factores estímulo y personales como determinantes de la formación de la imagen de marca de los destinos turísticos: un estudio aplicado a los turistas que visitan un destino vacacional. Cuadernos de Economía y Dirección de la Empresa, 43, 37-63. Recuperado de http://www.redalyc.org/articulo. oa?id=80713681002
Venegas Montes G. (2006). Ecoturismo instrumento de desarrollo sostenible. Universidad de Antioquia, biblioteca digital de acceso abierto UdeA, 1-63. Recuperado de http://hdl.handle. net/10495/149.

World Summit on Sustainable Tourism +20. (2015). Carta mundial del turismo sostenible. Sesion plenaria de la Cumbre en Vitoria-Gasteiz, 1-34. Recuperado de http://cartamundialdeturismosostenible2015.com/la-carta-mundial-de-turismo-sostenible/ 